\title{
Evaluation of the Effective Factors on Social Interactions in the Design of Public Libraries
}

\author{
Reza Askarizad
}

\begin{abstract}
Nowadays, the interaction of people in the world is deemed a controversial topic and consequently, the creation of an appropriate context for interacting with individuals is one of the issues that is considered by architects in many designs. In this research, it has been endeavored to consider the factors affecting social interactions in the design of public libraries through the descriptive-inferential analysis. The results of this research reveal that in the architectural spaces that have been designed with open-configured plans, spatial integrity and sociability will increase. On the other hand, the factors such as depth and the level of privacy are also reduced. Therefore, in designing a public library with an approach toward social interaction, there should be a variety of open and closed-configured spaces in the plan that allow users to choose the space they optionally want and in which they would enjoy in their own presence by choosing their own activities.
\end{abstract}

Keywords: public library; Rasht National Library; social interactions; social sustainability; space syntax

\section{INTRODUCTION}

Human beings are social creatures in the sense that their survival condition depends on establishing communications and social interactions. Sociability is a procedure that prepares individuals for collective life [1]. Nowadays, the interaction of people in the world is a quite significant topic and consequently, the creation of an appropriate context for interacting with individuals is one of the issues that is considered by architects in many designs [2].

Studies have indicated that people are satisfied to be in the places which are the source of interactions [3]. The opportunity to see, hear and meet others can be the main attraction in urban spaces [4]. Being amongst others provides a rich sense of experience that brings a special quality to the environment. The attractiveness of the public environment is not only because of the buildings; rather, it depends on the presence of the people and the human events occurring there [5].

Meanwhile, a library is a kind of a public space; and a public space, according to its definition, should be a platform for the use and communication of citizens and can help users to increase the social interaction opportunities within it [6]. Based on its definition, a library is a building that preserves and stores books, papers and periodicals which may be read or lent out [7]. Nonetheless, public libraries have evolved in the present era and have changed from mere cultural institutions which preserve books, cultural heritage and in general, history and culture, into social, interactive and media environments where not only modern technologies take place in, but they can be considered as a manifestation of people's interactions, knowledge and public culture in its new form [8].

Despite the positive efforts made in the recent years, the active public libraries in Rasht still face challenges in attracting and retaining their users through the provision of au courant services to meet their scientific, cultural and recreational requirements. Most of the time, the existing libraries in Rasht are vacant, or the presence of users is just for studying their own educational books during the time of university or school examinations. Accordingly, the need to create spaces with an approach toward audience attraction in public libraries seems to be necessary. In this way, it has been attempted to consider the factors affecting social interactions in the design of public libraries in order to maximize their level of attraction and the interaction of the audience, as much as possible, from the culture of reading books. In this regard, the following questions have been posed in order to obtain appropriate answers:

1) How can social interactions be considered in library designs?

2) What influences do social interactions have in the design of public libraries?

It seems that the spatial configuration of libraries can affect the level of the attraction and interaction of the audience as much as possible. Additionally, it is assumed that open-configured plans have a positive effect on interactional spaces and can improve the level of people's attraction toward public libraries.

\section{THEORETICAL FRAMEWORK}

\subsection{Social Sustainability and Its Role on Sociability}

Sustainable design is a sort of a scheme that aims to satisfy today's requirements without sacrificing the resources for future generations [9]. Social sustainability captures the human dimension of the sustainability discourse and accentuates the people and communities [10]. In other words, social sustainability is the ability of a society or an individual to cope with problems in a way that provides both their needs and the subsequent generations [11]. Therefore, social sustainability is a human and social discourse that investigates the human lifestyle and its effects on social interactions in the course of time. However, there is a consensus among the researchers that the social dimension of sustainable development has been severely neglected in its trinary facets [12].

Rapoport introduces urban space as an urban environment that includes a set of communications and interactions [13]. Sociability in a public space depends on promoting social interactions [14], attracting individuals and 
groups [15], easy accessibility [16], social security [17], creating a mental image and legibility [18] and creating a lively \& dynamic atmosphere [2]. Sociability in public spaces is based on the people's requirement to sense social belongings and interact with each other; and this will be possible in a supportive social space along with providing physiological comfort [19], claim of the realm, sense of ownership and social justice within the space [3].

If the social needs of people are balanced with the feeling of individual independence derived from privacy, then, social relations become easier. Physical privacy is the pre-requisite for most social behaviors; in an environment in which physical secrecy exists, a wider range of personal choices is created [2]. That is precisely why people stay in a good place for a longer period than they really need - because they actually enjoy being there [4]. Therefore, in order to answer the questions and hypotheses of this research, and evaluate the effective factors on social interactions in the design of public libraries, various definitions of this variable have been considered from the viewpoint of the experts in this field (Tab. 1).

Table 1 Definition of Sociability from the Viewpoint of Experts

\begin{tabular}{|c|l|c|}
\hline Theorist & \multicolumn{1}{|c|}{ Definition of Sociability } & Keywords \\
\hline Kevin Lynch & $\begin{array}{l}\text { He considers legibility as one of the crucial factors affecting the sociability of an urban setting and } \\
\text { defines it as recognizing the components of a city in an integrated framework in our minds [18]. }\end{array}$ & Legibility, Mental Image \\
\hline Bill Hillier & $\begin{array}{l}\text { He identifies spatial configuration as the most important feature of sociability and declares that the } \\
\text { intelligibility and permeability of a milieu have an indispensable role on attracting people [20]. }\end{array}$ & $\begin{array}{c}\text { Spatial Configuration, } \\
\text { Intelligibility, Permeability }\end{array}$ \\
\hline Jan Gehl & $\begin{array}{l}\text { In defining urban sociability, he puts emphasis on the inviting sense of the space more than all its } \\
\text { other features and considers it as an important factor in the overall attractiveness of the city [4]. }\end{array}$ & An Inviting Space \\
\hline Irwin Altman & $\begin{array}{l}\text { He declares that the factors such as place attachment and sense of identity can be deemed as crucial } \\
\text { factors on the creation of an unanimous community [21]. }\end{array}$ & $\begin{array}{c}\text { Place Attachment, Sense of } \\
\text { Identity }\end{array}$ \\
\hline Jon Lang & $\begin{array}{l}\text { He describes social spaces as welcoming places and believes that such spaces are environments that } \\
\text { can improve the human experience and that also have a human scale [19]. }\end{array}$ & $\begin{array}{c}\text { Welcoming Places, Human } \\
\text { Scale }\end{array}$ \\
\hline Robert Gifford & $\begin{array}{l}\text { He remarks that the factors such as cognitive maps, territoriality, and sense of place are considered as } \\
\text { effective factors on human behavior in public spaces [22]. }\end{array}$ & $\begin{array}{c}\text { Cognitive Maps, Territoriality, } \\
\text { SOP }\end{array}$ \\
\hline Lawrence Halprin & $\begin{array}{l}\text { He considers spaces that allow citizens to choose freely with a great deal of diversity as societal } \\
\text { spaces, and believes that these spaces give the city a special quality and personality [23]. }\end{array}$ & A Great Deal of Diversity, \\
\hline Paul Zucker & $\begin{array}{l}\text { He names social spaces as elements that make the society in the true sense of community rather than } \\
\text { the mere aggregation of individuals [24]. }\end{array}$ & True Sense of Community \\
\hline
\end{tabular}

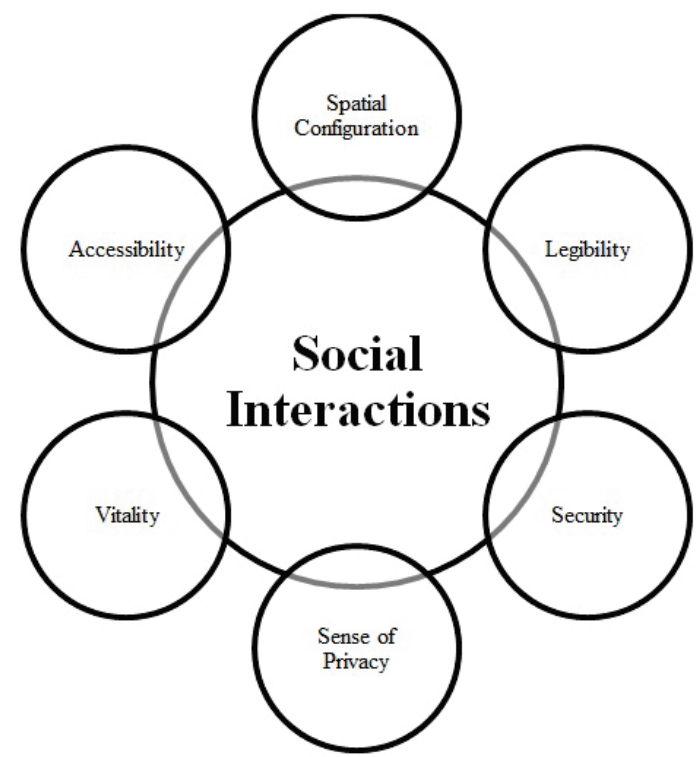

Figure 1 Factors Affecting Social Interactions in Public Spaces

\subsection{Social Interactions}

Social interaction means establishing a relationship between two or more people that leads to a reaction among them, and this kind of reaction is cognizant to both parties [25]. Therefore, meaningless relationships do not go under this definition [26]. According to Jan Gehl [4], three types of activities have been identified in public spaces and they are the following: necessary activities, optional activities, and social activities. Among them, social activities mainly refer to the interaction that people engage in, such as playing with others, greeting others, and talking to others. Even passive contacts, such as eye contact, watching events, and listening to others, are considered to be social activities [27].

In his book, Humphrey Osmond uses the terms "Sociopetal" and "Sociofugal", which express the qualities of space that bring people together or separate them from one another [2]. In the poor quality areas of the city, it is only possible to find necessary activities; in other words, people only do the work that they are required to do. In high quality urban areas, not only are the essential activities done in proper conditions, but also, many recreational and societal activities are done in a good way [4]. According to the previous study literature on the assessment of the factors affecting socialization in public spaces and from the viewpoint of experts and theoreticians, six factors have been identified as influential items in order to promote social interactions in the design of public spaces (Fig. 1).

\section{CASE STUDIES}

Rasht is one of the major metropolises in Iran, the capital of the Gilan Province in northern Iran and it is recognized as the third most visited touristic city in Iran. The historical date of Rasht is likely to go back to the pre-Islamic period and at least the Sassanid era [28]. For many years, the Municipality Square has been the heart of Rasht and a place at which critical activities and traditional events take place. It is located in the central part of the city and near the main bazaar and the Green Square (another historical square in Rasht) and it houses many cultural and administrative buildings [25]. In 
this research, the intention is to scrutinize two critical libraries in Rasht, named the Rasht National Library and the Emam Hasan Mojtaba Library.

The Rasht National Library is located in the central part of this city and it is adjacent to the Municipality Square. Based on the documents and evidence, its construction began in 1927 on a site granted by the former mayor of Rasht to the population community of the publishing house for the construction of a library. The construction of the building was carried out simultaneously with the construction of a series of administrative and public buildings in the north of Iran and in the First Pahlavi era, which is seen as a milestone for the formation of the city's historical texture (Fig. 2). The Rasht National Library is the first national library in Iran and one of the oldest public libraries independent from governmental institutions. In this regard, due to the historical value of the building and its popularity among citizens, it has been chosen as a case study in this research. The library's total number of members is approximately 20,000 and on average, about 1,500 people use this library each day [29].

Another studied case is located in the Green Square of Rasht, which is 400 meters away from the National Library. The Emam Hasan Mojtaba Library was constructed in 1968, in the Second Pahlavi era, and is seen as another important public library in Rasht. The Green Square was designed based on the paradigms of the Persian Gardens and its library plays the role of a pavilion on it and its architecture is based on the vernacular architecture of Rasht (Fig. 3). Therefore, the intention was to assess these two case studies in order to generalize the subject matter.
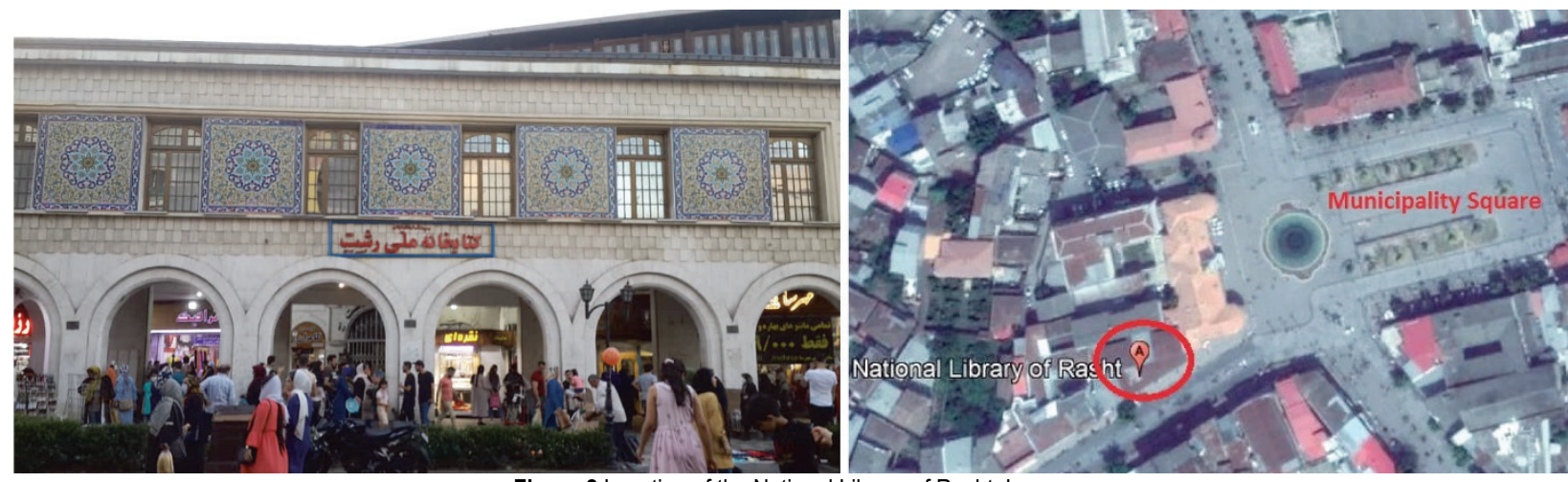

Figure 2 Location of the National Library of Rasht, Iran
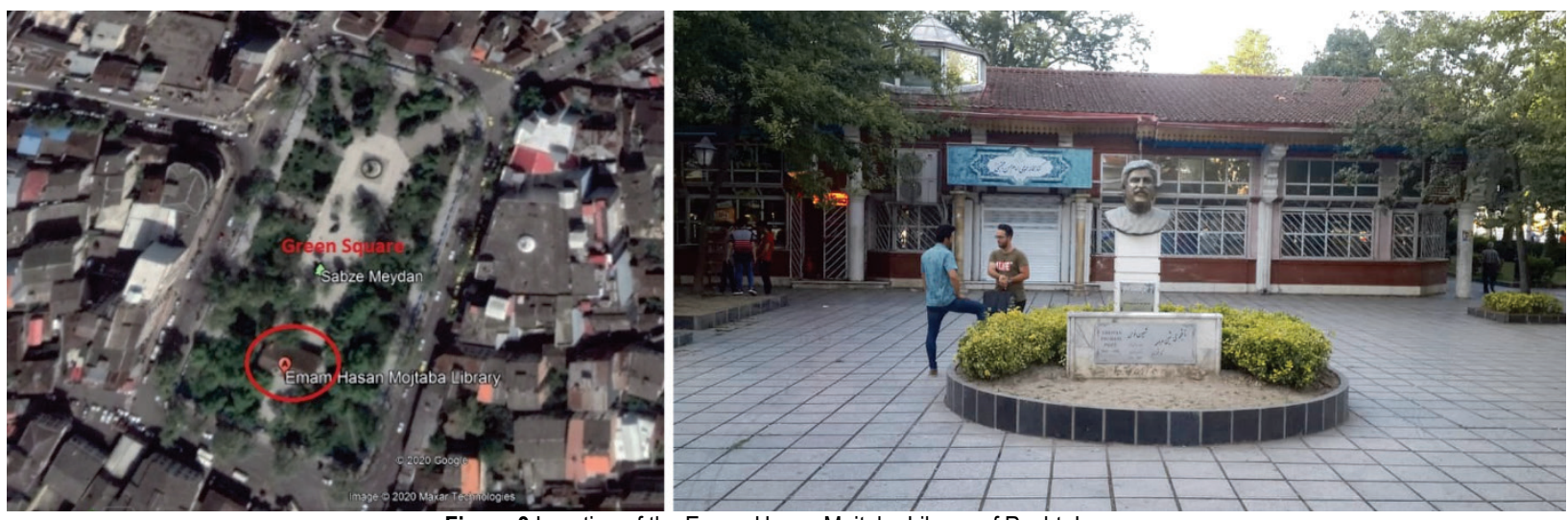

Figure 3 Location of the Emam Hasan Mojtaba Library of Rasht, Iran

\section{RESEARCH METHODOLOGY}

The research method has been applied quantitatively. In the first section, the library documents have been reviewed and through this, the theoretical principles of library design have been developed. In order to obtain the appropriate information from the existing conditions, field methods and taking notes have also been used in order to obtain the objectives of this research. Moreover, according to the questions elaborated in this research, by using the SpaceSyntax methodology, the relationship between all spaces in the National Library of Rasht have been analyzed and the results have been presented as mathematical and graphical parameters - with a descriptive-inferential analysis. The method for gathering data is using library resources (papers, books, journals and theses) and the research data have been evaluated by using scientific methods and simulations.

Furthermore, the $\boldsymbol{U C L}$ Depthmap 10 software has been used to assess the social logic of the spatial configuration of the building in order to understand its legibility and syntactical logic. Therefore, after drawing the architectural floor plan of the case studies in the AutoCAD software, the file was imported to the Depthmap software. By using the variables and components affecting social interactions, the spaces within the Rasht National Library were then analyzed and the output was extracted in the form of graphs \& digital 
numbers. Accordingly, the principles derived from the research for designing a library with an approach toward social interaction were presented.

The Space-Syntax theory was introduced in 1976 by Professor Bill Hillier and his colleagues at the University College London. It is founded on the concept that the spatial configuration of the built environment determines how the space is experienced, explored and comprehended [20,30]. By analyzing a series of spatial characteristics, Space-Syntax helps designers understand the role of spatial configurations in shaping the patterns of human behavior and it helps them estimate the social effects of their designs. This analysis model enables us to study the causal correspondence between the architectural forms and its impact on promulgating social interactions among people [31]. Numerous studies in the field of architecture have validated this method $[8,32,33]$.

The variables used in this software in order to evaluate human behavioral patterns and their social impact estimation are Connectivity, Intelligibility, Mean Depth and Choice. In order to equate them with the components that affect social interactions, it can be argued that the functional concept of Connectivity is accessibility. Furthermore, the functional concept of Intelligibility is defined by the correlation between Integration and Connectivity, which can be considered tantamount to legibility. In order to equivalent the privacy component, the Mean Depth variable was used, and it is based on the separation of a particular space from the overall spatial configuration. Moreover, the Choice variable was used in order to measure the level of the security of the space.

\section{RESULTS}

\subsection{Analysis of the Rasht National Library using Space Syntax}

The results of the analysis for the interior space of the Rasht National Library using the Depthmap software in the test of the axial line indicate that the level of accessibility and integration on the second floor is more than the level of accessibility and integration on the first floor. According to the analysis carried out by the Space-Syntax methodology, the integration level of the first floor is 9.00 , whereas the integration level of the second floor is 39.73. On the other hand, the level of connectivity on the first floor is 22 , but on the second floor, the range of connectivity is 99 (Tab. 2).

Additionally, the results obtained from the analysis of the Emam Hasan Mojtaba Library reveal that the level of integration on the second floor is higher than on the first floor. Accordingly, the quantitative amount of integration on the first floor is 4.43. However, the level of integration on the second floor of this library is 8.87 . Moreover, the quantitative range of connectivity on the first floor is 8 , while the same range on the second floor is equivalent to 7. The data elucidate that despite better accessibility on the first floor, the sociability process on the second floor is much higher (Tab. 2). The analysis is visually denoted into a chromatic scale so that the integrated spaces are presented in red, while the segregated spaces are presented in blue.
Additionally, the results of the correlation test based on the correlation between integration and connectivity show that legibility on the first floor is higher than on the second floor. In other words, the first floor of the Rasht National Library has a higher degree of intelligibility compared to its second floor. Moreover, the value of $R^{2}$ for the first floor is 0.83 and 0.79 for the second floor.

Likewise, the findings obtained from the correlation between integration and connectivity illustrate that the intelligibility level on the first floor is higher than on the second floor. Quantitative data calculations indicate that the amount of $R^{2}$ for the first floor is 0.89 , while the $R^{2}$ quantity for the second floor is 0.81 . As a result, it can be interpreted that spaces which have an open-configured characteristic in their formation will present better integration but less legibility.

In terms of other variables affecting social interactions, the same can also be mentioned regarding components such as security, accessibility and privacy. Therefore, analyzing the variables affecting these components with the syntactical analysis in the Rasht National Library suggests that the spaces such as the Manager's Office and Library Shelves, with the choice value of 182, are more secure than other spaces. Furthermore, the assessment of the Accessibility variable indicates that the Manager's Office and Library Shelves adjacent to the staircase, with a connectivity rate of 22 , have the best access on the first floor plan of the library. Moreover, in relation to the sense of privacy in the Rasht National Library, it should be noted that the Library Shelves and the toilet, located on the southwest side of the library and with the mean depth value of 2.74 , have the highest spatial depth. This means that these spaces provide the highest sense of privacy and confidentiality in the Rasht National Library (Fig. 4).

The results obtained from the behavioral patterns of users in the spaces of the Rasht National Library by using the visibility graph analysis indicate that the Reading Hall of the library space, with an Isovist Area of 269.66, has the greatest effect on the behavioral pattern of users among the spaces of the Rasht National Library. After that, the Lobby space, with an Isovist Area of 172.94, has the greatest effect on the behavioral patterns of users. Accordingly, the space of the Main Reading Hall has more visibility and scope of view, which is visible from a particular point. Moreover, the analysis of the VGA test in the Emam Hasan Library has indicated that the Lobby space, with an Isovist range of 154.86, has the greatest effect on the behavioral patterns of the occupants (Tab. 4). As a result, simulation studies reveal that identifying spaces such as lobbies in the central organization of public places may have an indispensable role on interactional activities.

By analyzing the findings regarding the effective factors on social interactions in the studied libraries, it can be concluded that the rate of spatial integration will increase in the architectural spaces which have been designed with open plans. On the other hand, factors such as depth and the degree of privacy are also decremented. As it was mentioned in the analysis of the Space-Syntax methodology regarding the second floor plan of the library which resembles an open- 
configured space, the library is equally well-versed in terms of spatial integrity, and reducing the rate of mean depth has made it livelier.

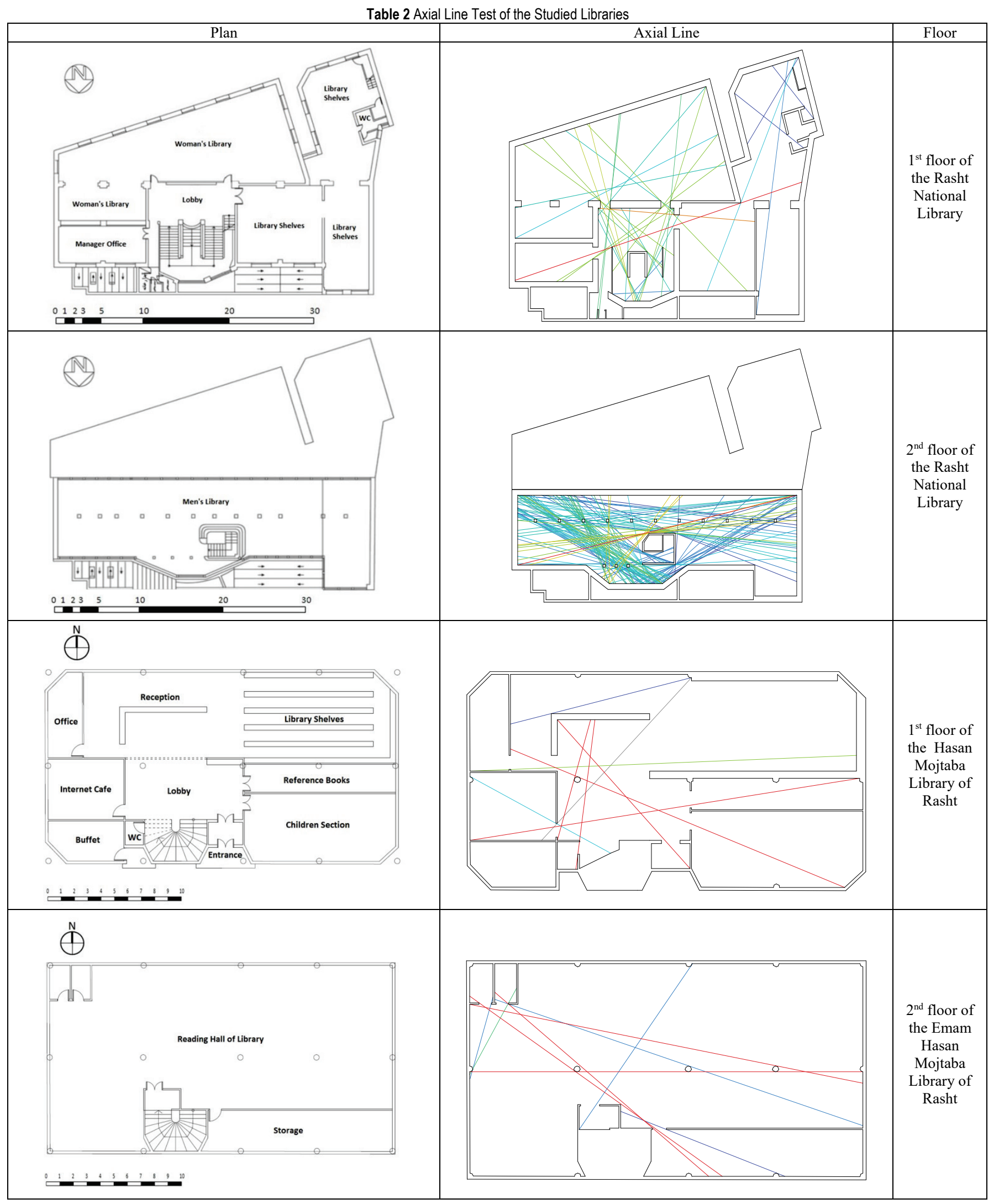


There should also be specific propensity toward the creation of spaces with more depth in order to meet the requirements of the people's sense of privacy. In this way, security is also relative and influential on the factors such as vitality. According to the analysis, the range of integration in high-depth spaces is lower than that of low-depth spaces. In other words, by increasing the degree of integration, the mean depth decreases, which is the conspicuous reciprocal synergy.
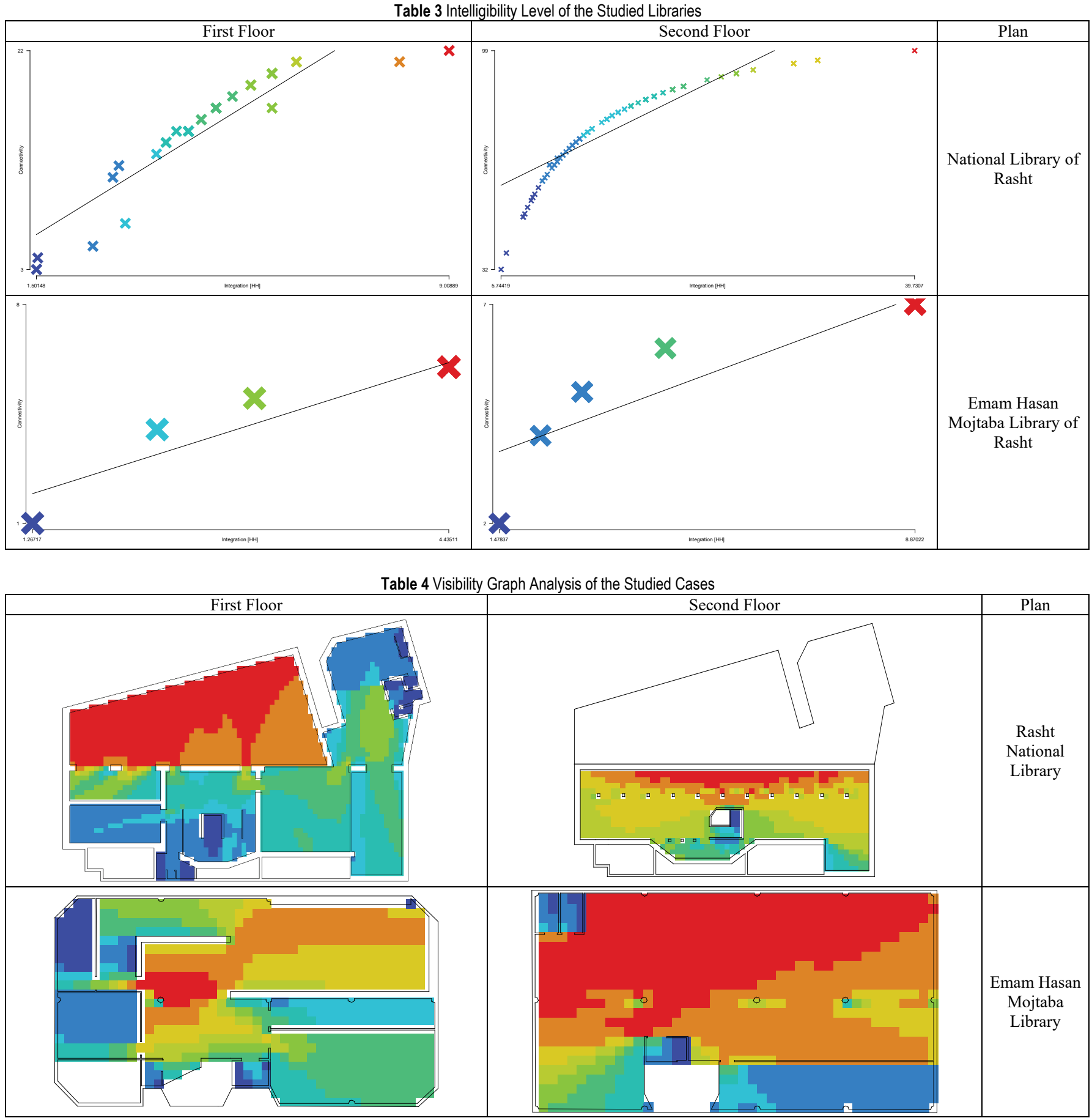

\section{CONCLUSION}

The objective of this study was to evaluate the factors affecting social interactions in the design of public libraries. Nowadays, the confinement of libraries in administrative buildings with a conventional and formal atmosphere and the complete separation of such buildings from the daily life of people has prevented constructive interactions from happening between people, and in the libraries, which has greatly diminished the number of people visiting them in Iran. One of the reasons for the lack of interest in public libraries in Iran is the lack of attention of architects and 
employers to the attractiveness of library spaces in their designs and planning phases. This makes it increasingly obvious that it is necessary to evaluate the factors affecting social interactions in the design of public libraries in order to expand the culture of reading within the society.

The results of the analysis regarding the interior space of the Rasht National Library by using Space-Syntax in the test of the axial line indicate that the level of spatial integration on the second floor is more than the integration level on the first floor. However, the results of the correlation test between integration and connectivity reveal that the first floors of the studied cases have a higher level of intelligibility compared to the second floors. Moreover, the results from the Space-Syntax analysis in the Rasht National Library illustrate that the spaces such as the Manager's Office and Library Shelves are more secure than other spaces. Furthermore, spaces such as the Manager's Office and the Library Shelves, which are adjacent to the staircase, have the best accessibility on the first floor plan of the library. However, in the Emam Hasan Mojtaba Library, the Lobby space has the best sociability, accessibility and security potential among all other spaces.
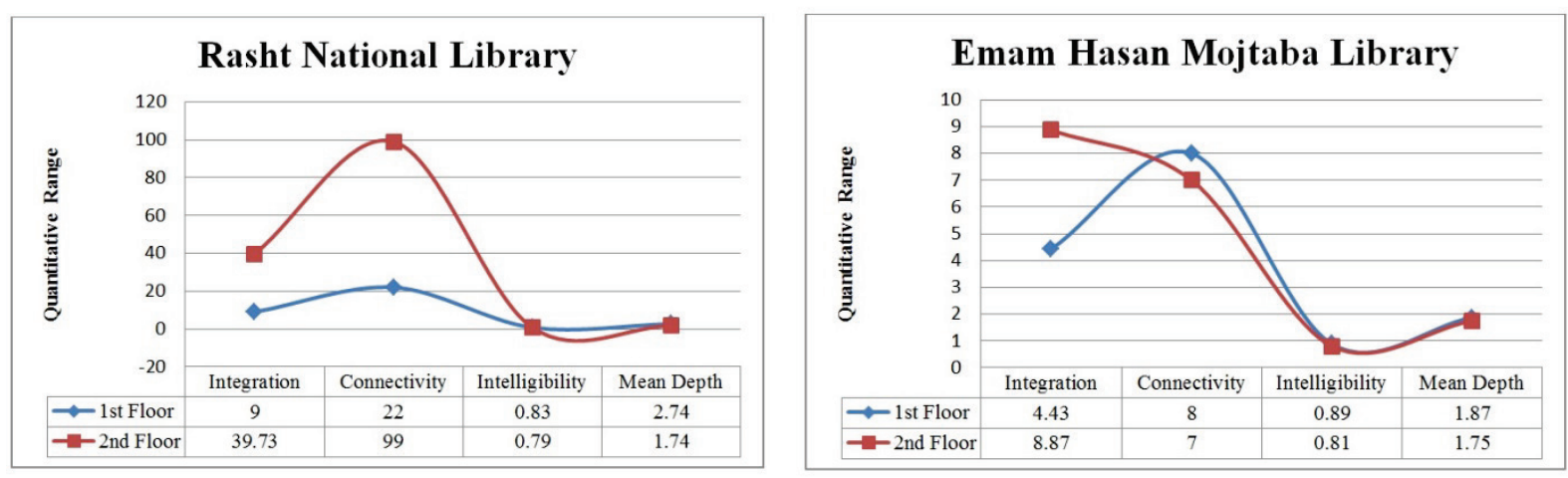

Figure 4 Quantitative Data Obtained from Syntactical Analysis of the Studied Cases

Based on the Space-Syntax analysis for the studied libraries, the following results can be considered for acquiring more sociable spaces in library designs:

1 - Plans that are compact and have less longitudinal and latitude stretches can be more legible.

2 - The location of the main entrance is better when it is near the central circulation space and in front of the visitor's point of vision.

3 - Paying attention to the private and public hierarchy that have been tailored to the function can lead to more legibility and can create a sense of privacy.

4 - The use of open-configured spaces that can provide convenient movement and visual communication can enhance the sociability and security of architectural spaces. 5 - The use of long or narrow corridors reduces the movement and visual accessibility and creates confusion among the users who are present within the space.

6 - Using furniture that leads to the creation of personal territory has a positive impact on the efficiency and sociability of libraries.

In general, it can be concluded that in the architectural spaces that have been designed with open-configured plans, the rate of spatial integrity and sociability will increase. On the other hand, the factors such as depth and the degree of privacy will also be diminished. There is also a particular need for the creation of spatial depth in order to meet people's privacy requirements. In this regard, security is also relative and influential on the factors such as vitality. Therefore, in designing a public library with an approach toward social interaction, there should be a variety of open and closed spaces available in the plan that would allow users to choose the space they optionally want and in which they would enjoy in their own presence by choosing their own activities. Furthermore, according to the research findings, it can be concluded that the use of factors which are effective on social interactions in the design of public libraries can lead to the socialization of these spaces and their growing popularity among citizens regarding the culture of book reading. Finally, and in response to the hypothesis of this research, it can be declared that the spatial configuration of public spaces has an undeniable and indispensable role on interactional spaces. However, despite the positive effect of an open-configured plan on the social logic of spaces, it may also decrement the level of spatial legibility in these spaces in comparison to center-organized plans.

\section{REFERENCES}

[1] Talen, E. (2007). Design for Diversity: Evaluating the Context of Socially Mixed Neighbourhoods. Journal of Urban Design, 11(1), 1-32. https://doi.org/10.1080/13574800500490588

[2] Lang, J. (1987). Creating architectural theory: The role of the behavioral sciences in environmental design. New York: Van Nostrand Reinhold.

[3] Alexander, C., Ishikawa, S., \& Silverstein, M. (1977). A Pattern Language: Towns, Buildings, Construction (Center for Environmental Structure Series). Oxford, Oxford University Press.

[4] Gehl, J. (1987). Life between Buildings: Using Public Space. New York: Island Press.

[5] Bechtel, R. \& Churchman, A. (2002). Handbook of Environmental Psychology. New York: John Wiley \& Sons.

[6] Thompson, J., History of Principles of Librarianship. 1977, London: Clive Bingley Press.

[7] Moghadam, C. R. \& Askarizad, R. (2019). English for Architecture Students. Rasht: Kadusan. 
[8] Askarizad, R. \& Safari, H. (2020). Investigating the role of semi-open spaces on the sociability of public libraries using space syntax (Case Studies: Sunrise Mountain and Desert Broom Libraries, Arizona, USA). Ain Shams Engineering Journal, 11(1), 253-264. https://doi.org/10.1016/j.asej.2019.09.007

[9] Sassi, P. (2006). Strategies for Sustainable Architecture. London: Taylor \& Francis. https://doi.org/10.4324/9780203480106

[10] Dempsey, N., et al. (2011). The social dimension of sustainable development: Defining urban social sustainability. Sustainable Development, 19(5), 289-300. https://doi.org/10.1002/sd.417

[11] Magis, K. (2010). Community Resilience: An Indicator of Social Sustainability. Society \& Natural Resources, 23(5), 401-416. https://doi.org/10.1080/08941920903305674

[12] Colantonio, A. (2007). Social Sustainability, An Exploratory Analysis of its definition Assessment Methods, Metrics and Tools. Oxford: The Oxford Institute for Sustainable Development.

[13] Rapoport, A. (1984). Culture \& the Urban Order: The City in Cultural Context. Boston: Allen and Unwin.

[14] Sennette, R. (1974). The Fall of Public Man. New York: Reissue edition.

[15] Whyte, W. (1980). The Social Life of Small Urban Spaces. Maryland: Tuxedo.

[16] Carr, S., et al. (1992). Public Space. Massachusetts: Cambridge University Press.

[17] Marcus, C. \& Francis, C. (1998). People Places: Design Guide Lines for Urban Open Spaces. New York: Van Nostrand Reinhold.

[18] Lynch, K. (1960). The Image of the City. Massachusetts: The M. I. T. press.

[19] Lang, J. (1994). Urban Design, American Experience. New York: Van Nostrand Reinhold.

[20] Hillier, B. \& Hanson, J. (1984). The Social Logic of Space. Cambridge: Cambridge University Press. https://doi.org/10.1017/CB09780511597237

[21] Altman, I. \& Low, S. M. (2012). Place Attachment (Human Behavior and Environment (12)). New York: Springer.

[22] Gifford, R. (1987). Environmental Psychology: Principles and Practice. Boston: Altyn and Bacon.

[23] Halprin, L. (1972). Cities. Massachusetts: The MIT Press.

[24] Zucker, P. (1970). Town and Square, from the Agora to the Village Green. Massachusetts: the MIT Press.

[25] Askarizad, R. \& Safari, H. (2020). The influence of social interactions on the behavioral patterns of the people in urban spaces (case study: The pedestrian zone of Rasht Municipality Square, Iran). Cities, 101, p. 102687. https://doi.org/10.1016/j.cities.2020.102687

[26] Argyle, M. (2009). Social Interaction. New Jersey: Aldine Transaction.

[27] Huang, S. C. L. (2006). A Study of Outdoor Interactional Spaces in High-rise Housing. Journal of Landscape and Urban Planning, 78(3), 193-204. https://doi.org/10.1016/j.landurbplan.2005.07.008

[28] Askarizad, R., Safari, H., \& Pourimanparast, M. (2017). The influence of organizing historical textures on citizenry satisfaction in the old texture neighbourhoods of Rasht. Emerging Science Journal, 1(3), 118-128. https://doi.org/10.28991/ijse-01114

[29] Guilan, C. H. O. O. (2010). Rasht National Library. Publishing of the Heritage and Tourism Industries Organization: Rasht.
[30] Hillier, B., Leaman, A., \& Stansall, P. (1976). Space Syntax. Environment and Planning B: Urban Analytical and City Science, 3(2), 147-185. https://doi.org/10.1068/b030147

[31] Askarizad, R. (2017). Influence of Socio-Cultural Factors on the Formation of Architectural Spaces (Case Study: Historical Residential Houses in Iran). Creative City Design, 1(3), 4454.

[32] Asif, N., et al. (2018). Reflection of cultural practices on syntactical values: An introduction to the application of space syntax to vernacular Malay architecture. Frontiers of Architectural Research, 7(4), 521-529. https://doi.org/10.1016/j.foar.2018.08.005

[33] Jeong, S. K. \& Ban, Y.U. (2011). Computational algorithms to evaluate design solutions using Space Syntax. ComputerAided Design, 43(6), 664-676. https://doi.org/10.1016/j.cad.2011.02.011

\section{Author's contact:}

\section{Reza Askarizad}

Department of Architecture, Rasht Branch, ACECR, Rasht, Iran reza.askarizad@gmail.com 